\title{
Method of Obtaining Casein from Skim Milk using Oligochitosans
}

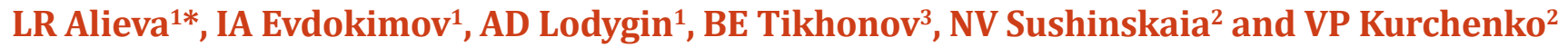 \\ ${ }^{1}$ North-Caucasus Federal University, Russia \\ ${ }^{2}$ Belarusian State University, Belarus
}

${ }^{3}$ AN Nesmiyanov Institute of Organo element Compounds of Russian Academy of Sciences, Russia

*Corresponding author: LR Alieva, North-Caucasus Federal University, Stavropol, Russia

To Cite This Article: LR Alieva, IA Evdokimov, AD Lodygin, BE Tikhonov, NV Sushinskaia, et al., Method of Obtaining Casein from Skim Milk using Oligochitosans. 2020 - 8(4). AJBSR.MS.ID.001297. DOI: 10.34297/AJBSR.2020.08.001297.

Received: 眥 April 07, 2020; Published: 眥 April 20, 2020

\begin{abstract}
The interaction of milk proteins and oligochitosansis based on formation of electrostatic complex between negatively charged casein micelles and positively charged polysaccharide groups. At low concentrations of oligochitosans, partial interaction with milk proteins occurs. Maximum protein coagulation (90\%) is achieved in equivalence zone at the concentration of oligochitosans: $45.3 \mathrm{kDa}-0.88 \times 10^{-4} \mathrm{M}$; $25.4 \mathrm{kDa}-1.57 \times 10^{-4}$ $\mathrm{M} ; 7.7 \mathrm{kDa}-5.19 \times 10^{-4} \mathrm{M} ; 1.5 \mathrm{kDa}-26.67 \times 10^{-4} \mathrm{M}$. In these concentrations, taking into account the molecular weight and degree of deacetylation of oligochitosans, the total content of protonated amino groups is equal $2.4 \times 10^{-4} \mathrm{M}$. When t protein content in skimmed milk is $3.0 \%-3.2 \%$, oligochitosans of any molecular weight and degree of deacetylation can be used for casein coagulation, important that the final concentration of amino groups should be $2.4 \times 10^{-4} \mathrm{M}$. It was determined that the use of the studied samples of oligochitosan allows to obtain coacervate where $1 \mathrm{~g}$ of oligochitosan binds $6.0-6.2 \mathrm{~g}$ of milk proteins.
\end{abstract}

Keywords: Oligochitosan, a-casein, b-casein, K-casein, b-lactoglobulin, a-lactalbumin, Protein Coagulation

\section{Introduction}

The combination of harmless nature and biological activity of chitosan creates prerequisites for its wide application in milk processing and casein production [1]. Due to the structure of casein micelle, at $\mathrm{pH}$ above 5.0 a large negative charge is concentrated on its surface. Chitosan at pH below 6.5 has a positive charge that enables ionic interaction of chitosan with casein. So adding chitosan to milk we can expect their coagulation and precipitation [2-4]. Chitosan is soluble in organic acids that causes difficulties for milk processing [3]. Oligochitosans are low-molecular-weight chitosan derivatives with a molecular weight between 2 and $50 \mathrm{kDa}$. They are highly soluble in water and do not influence on acidity when added to milk. There is a practical possibility to use oligochitosan to isolate casein from skimmed milk $[4,5]$. The effectiveness of the interaction of casein with oligochitosans depends on their molecular weight and the number of amino groups. The objective of the research was to obtain casein from skimmed milk using oligochitosans with different molecular weights.

\section{Materials and Methods}

The objects of the research were: skimmed cow milk (produced by JSC "Savushkin product", Russia) and oligochitosans with molecular weights of 45.3, 25.4, 7.7 and $1.5 \mathrm{kDa}$ with a degree of deacetylation (SD) of $86 \%$, obtained by the previously described method [6]. The molecular weight of oligochitosans was determined by viscosimetry and calculated using the Mark-Houwink equation; the degree of deacetylation was determined by conductometric titration. To study the process of casein coagulation, water solutions of oligochitosans with different molecular weights were added to skimmilk to the final polysaccharide concentration from $0.02 \%$ to $1 \%$ and a protein content of at least $3.1 \%$. The mixture was incubated for 30 minutes at $60^{\circ} \mathrm{C}$, and then centrifuged for 10 minutes at 9000 $\mathrm{g}$ to separate the coagulate. The obtained supernatants and protein precipitates were analyzed using electrophoresis in poly acrylamide gel at pH 8.8 in the presence of DDS-Na. The compliance of electro phoretic components with individual proteins was confirmed by protein standards (Sigma, USA). Thermo gravimetric analysis 
of casein complexes with chitosan was performed on "TA-4000 Mettler Toledo" (Switzerland). Measurements were performed in the temperature range of $25-600{ }^{\circ} \mathrm{C}$ in the air atmosphere at a heating rate of $5^{\circ} \mathrm{C} / \mathrm{min}$. The activation energy was determined by the Broydeau equation. The protein concentration was measured by biuret method.

\section{Results and Discussions}

Milk is a complex polydisperse mixture of casein micelles, fat globules, whey proteins, lactose and minerals. Protein components and fat globules at a pH of 5.0-6.2 are negatively charged and able to interact with oligochitosan. In our research we studied the effect of oligochitosan on milk components with a fat content of $3.2 \%$ at a $\mathrm{pH}$ of 6.0. The results of the research are presented in the table 1 (below). Analysis of the results shows that adding oligochitosan with a molecular weight of $25.5 \mathrm{kDa}$ to the milk with fat content of $3.2 \%$ results in fractionation into milk fat, casein and whey proteins. Adding oligochitosan to skim milk we can isolate casein fraction.

\begin{tabular}{|c|c|c|c|c|}
\hline Table 1: The influence of oligochitosan Mw $25.5 \mathrm{kDa}$ on milk proteins coagulation. & Fat content, $\%$ & Protein content, $\%$ \\
\hline Experimental conditions & $\mathbf{p H}$ & Fractions & 3,2 & 3,3 \\
\hline Milk with fat content 3,2 \% & 6,0 & no fractionation & 3,05 & - \\
\hline \multirow{3}{*}{$\begin{array}{c}\text { Milk with fat content 3,2 \% with0,5 \% } \\
\text { oligochitosan 25,5 kDa }\end{array}$} & 6,0 & milk fat fraction & 0,1 & 0,5 \\
\cline { 2 - 5 } & & whey & 0,05 & 2,8 \\
\hline Skimmilk & 6,0 & nofractionation & 0,1 & 3,3 \\
\hline $\begin{array}{c}\text { Skimmilkwith0,5 \% oligochitosan 25,5 } \\
\text { kDa }\end{array}$ & 6,0 & whey & 0,1 & 0,5 \\
\cline { 2 - 5 } & & Casein fraction & - & 2,8 \\
\hline
\end{tabular}

We investigated the process of skim milk proteins coagulation depending on the concentration of oligochitosans with different molecular weights at $\mathrm{pH}$ 6.0. We added water solutions of oligochitosans with molecular weights of 45.3, 25.4, 7.7 and 1.5 $\mathrm{kDa}$ in the final concentration from $0.02 \%$ to $1 \%$ to skimmed milk and observed coagulation. This process took place at $60{ }^{\circ} \mathrm{C}$ during

30 minutes.
The protein content in milk, after separation of the coagulate, depended on the concentration and molecular weight of oligochitosan (Figure 1A). The Figure 1B shows the composition of the proteins included in the supernatant. The coacervation of milk proteins did not occur in the absence of oligochitosan (Figure $1 \mathrm{~A}$ $\& 1 \mathrm{~B})$.

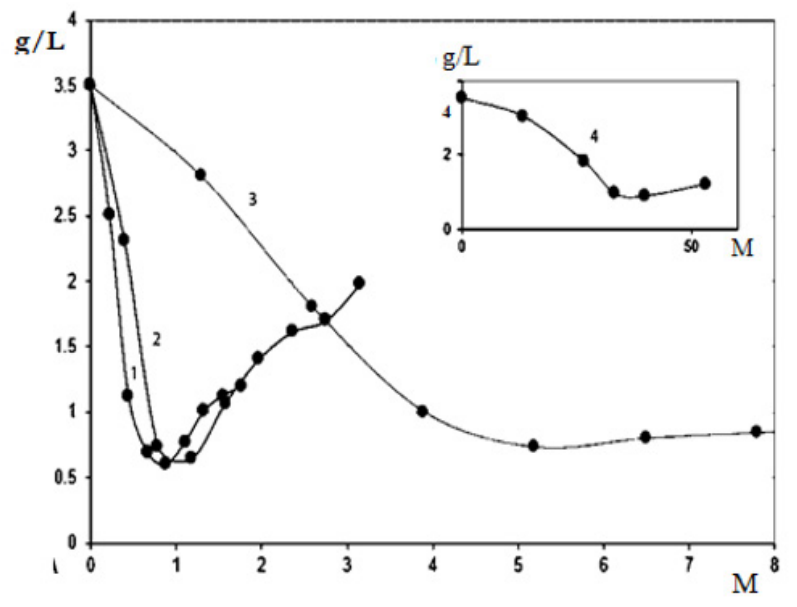

(a)

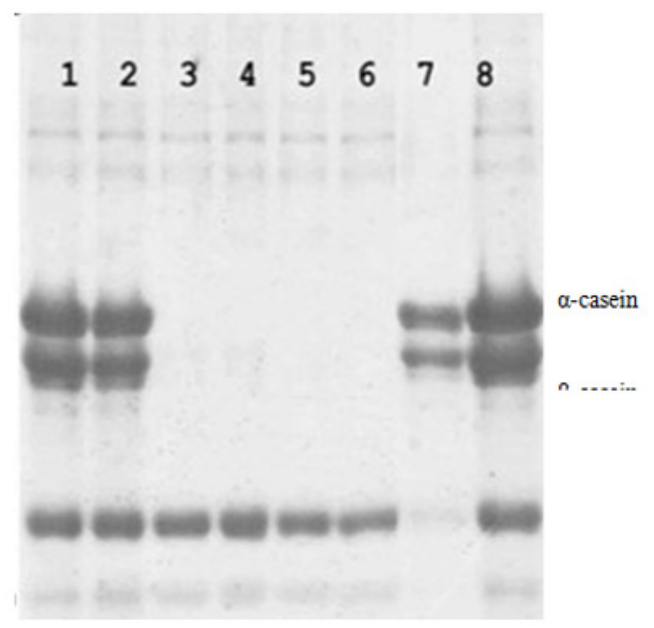

(b)

\section{Figure 1:}

(a) Dependence of casein content in supernatant on concentration of chitosan with molecular weight of 45.3 (1), 25.4 (2),7.7 (3) and 1.5 kDa (4),

(b) Electrophoretogramof casein in the presence of chitosan is $0.1-0.5 \% 25.4 \mathrm{kDa}$ (tracks 3 to 6 ), coagulated precipitate (track 7 ), milk proteins standards (tracks 8).

The amount of coagulated milk proteins increases with the concentration of oligochitosans. At low concentrations of oligochitosans, partial interaction with milk proteins takes place.
Maximum protein coagulation ( $90 \%$ ) is achieved respectively at the concentration of oligochitosans: $45.3 \mathrm{kDa}-0.88 \times 10^{-4} \mathrm{M}$; $25.4 \mathrm{kDa}-$ $1.57 \times 10^{-4} \mathrm{M} ; 7.7 \mathrm{kDa}-5.19 \times 10^{-4} \mathrm{M} ; 1.5 \mathrm{kDa}-26.67 \times 10^{-4} \mathrm{M}$. In these 
concentrations oligochitosans with different molecular weight and degree of deacetylation, the content of protonated amino groups remains the same $-2.4 \times 10^{-4} \mathrm{M}$. These results indicate that oligochitosans of any molecular weight and degree of deacetylation can be used for coagulation of casein from skimmed milk with a protein content of $3.0 \%-3.2 \%$. Key factor is the concentration of amino groups $2.4 \times 10^{-4} \mathrm{M}$. It is determined that the use of these samples of oligochitosans allows to obtain a coacervate in which $1 \mathrm{~g}$ of oligochitosan binds $6.0-6.2 \mathrm{~g}$ of milk proteins.

A further increase of oligochitosans concentration leads to decrease in the formation of coacervate of milk proteins. The precipitate contains all casein groups: $a, b$, and k-casein and traces of whey proteins (Figure 1B). The densest precipitate is formed when using oligochitosan 45.3kDa due to the fact that oligochitosan with a high molecular weight forms complex with larger number of casein micelles. It explains better precipitation comparing to lowmolecular polysaccharides.

To confirm the interaction of oligochitosans with casein we used differential scanning calorimetry (DSC) and thermo graviometry (TGA). For these samples of casein, mechanical mixture of casein with oligochitosan and lyophilically dried coacervate of casein with oligochitosan we determined the stages of thermal decomposition under programmed heating conditions from $30{ }^{\circ} \mathrm{C}$ to $600{ }^{\circ} \mathrm{C}$ at a speed of $5{ }^{\circ} \mathrm{C} / \mathrm{min}$ (reflected in the Figure 2, Profile 1). DTG profile shows that the mass loss of mechanical mixture of casein and oligochitosan (Figure 2, Profile 2) matches casein profile in thermal degradation peaks.

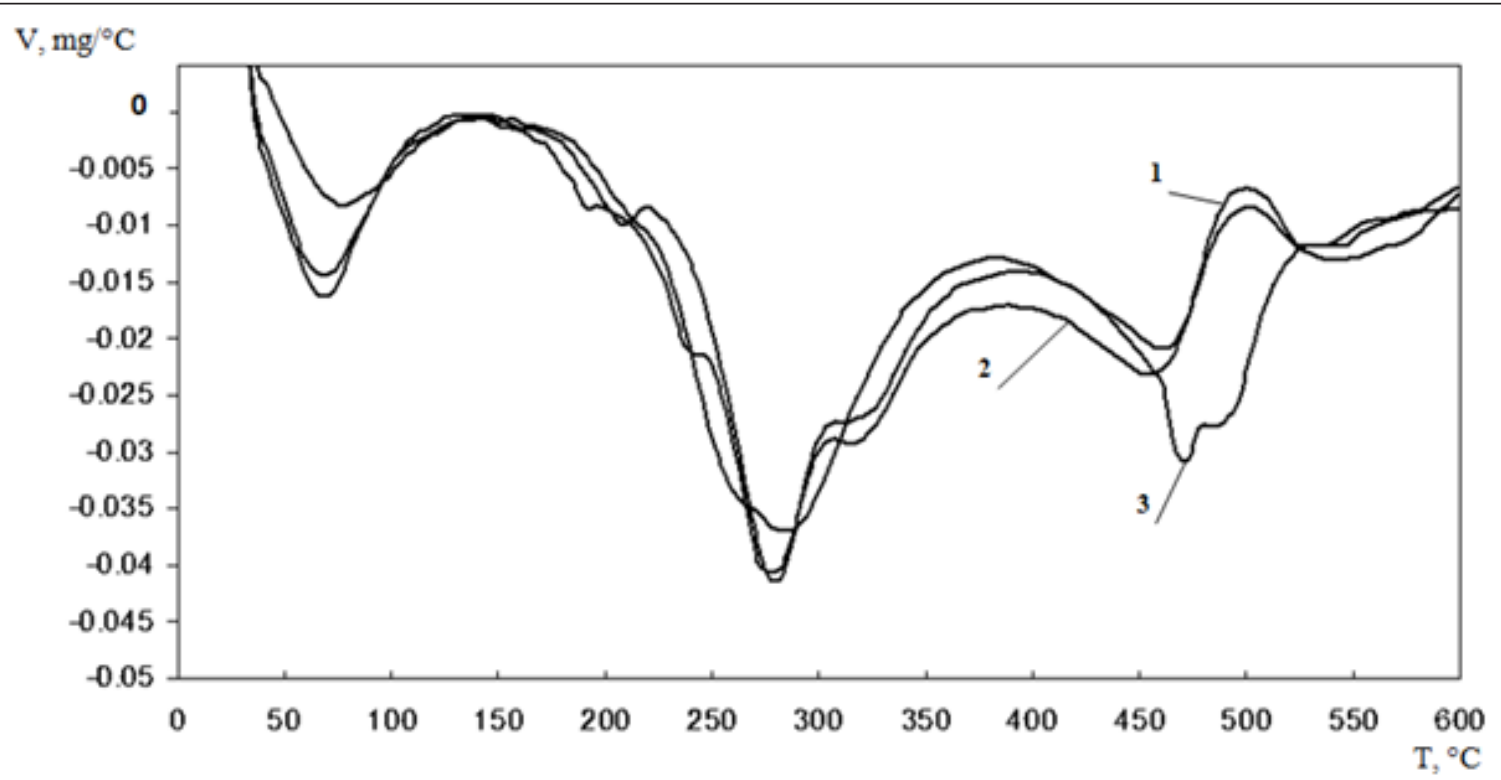

Figure 2: Profile of differential thermo graviometry of casein (1), Mechanical mixture of casein with oligochitosan (2) and Coacervate of casein with oligochitosan $25.4 \mathrm{k} \mathrm{Da}(3)$

In DTG profile of coacervate of casein with oligochitosan (Figure 2 , Profile 3) we see the decrease in the mass loss of casein coacervate with oligochitosan by 7.6-7.8\% compared to mechanical mixture of casein and with oligochitosan at a temperature of $287^{\circ} \mathrm{C}$. It proves the presence of strong complex of casein with oligochitosan. In addition, at temperature $476^{\circ} \mathrm{C}$ on DSC profile of coacervate of casein with oligochitosan appears the exothermic peak, not typical for mechanical mixtures. Its presence indicates possible complexation of oligochitosan with calcium ions present in casein. The activation energy (Ea) of thermal degradation of oligochitosan was $119 \mathrm{~kJ} / \mathrm{mol}$, casein $74 \mathrm{~kJ} / \mathrm{mol}$, and casein coacervate with oligochitosan $79 \mathrm{~kJ} / \mathrm{mol}$. The results indicate stabilization of casein in complex with oligochitosan.

The degree of coagulation of casein micelles in skim milk with oligochitosan $25.4 \mathrm{kDa}$ depends on its concentration and is measured by the number of amino groups interacting with protein.
The dependence of the amount of bound casein in skimmed milk on the concentration of oligochitosanis shown in the figure 3.

At low concentrations of oligochitosan and milk protein content of 3.1\% (Figure 3, Sector a), we observe partial formation of coagulate. At concentrations from $0.05 \times 10^{-4} \mathrm{M}$ to $1.37 \times 10^{-4} \mathrm{M}$ of oligochitosan with a molecular weight of $25.4 \mathrm{kDa}$ and deacetylation degree $86 \%$, the content of amino groups is $0.78 \times 10^{-2}-2.1 \times 10^{-2}$ M. In this case, with an excess of macroions of milk protein, only part of them can interact with a limited number of amino groups of oligochitosan macroion. At the concentration of oligochitosan from $1.45 \times 10^{-4} \mathrm{M}$ to $1.65 \times 10^{-4} \mathrm{M}$, we observe the equivalence zone (Figure 3, Sector b). In this sector, we reach maximum coagulation of milk proteins as the content of negatively charged casein groups is equivalent to positively charged oligochitosan groups. The interaction of casein and oligochitosan leads to the formation of electro-neutral complexes. Due to hydrophobic bonds they are 
forming aggregates precipitating from the system. The composition of complex coacervateis determined by stoichiometry of insoluble uncharged complex and depends on the charge ratio between milk proteins and oligochitosan.

When the concentration of oligochitosan increases, the amount of casein coagulate decreases (Figure 3, Sector c). Further increase in polysaccharide concentration prevents milk proteins from coagulation (Figure 3, Sector d). In this sector exceeding concentration of oligochitosan leads to the formation of stable colloid solution with milk proteins.

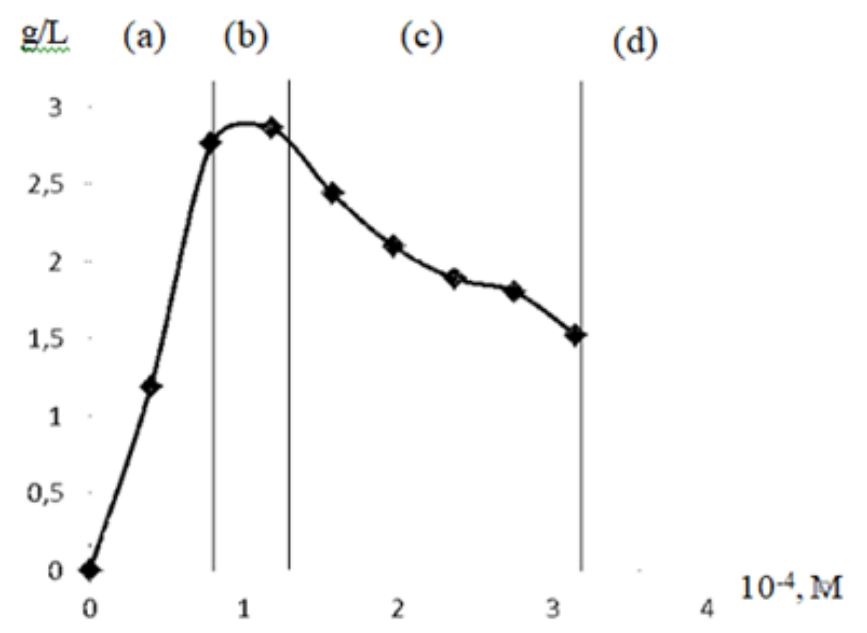

Figure 3: Dependence of bound casein in skim milk on the concentration of oligochitosan $25.4 \mathrm{kDa}$.

The process of interaction of milk proteins and oligochitosans at molecular level is caused by the formation of electrostatic complexes between negatively charged molecules of $\kappa$-casein micelles and positively charged groups of polysaccharide. Oligochitosans act as polycationic ligandslinked to casein micelles macroions. The process results in multi-point ionic interaction of oligochitosan molecules with casein micelles and whey proteins. The charge of polyionic complex decreased as the negatively charged macroions of proteins linked to oligochitosan. As a result, electro-neutral complex of oligochitosan with casein and whey proteins was formed. Aggregation of these complexes resulted in their precipitation in the form of coacervate $[1,5]$.

The proposed method for obtaining caseins using water-soluble oligochitosans opens the possibility of increasing the yield of milk protein to $90-92 \%$. In addition the whey obtained in this process has $\mathrm{pH}$ close to neutral and can be used for functional food production.
The research results provide theoretical prerequisites to use oligochitosans in the development and practical implementation of the original technology of casein separation from skimmilk.

\section{References}

1. Evdokimov IA, Alieva LR, Varlamov VP, Kharitonov VD , Butkevich TV, et al. (2015) Foods and raw materials 3: 29-39.

2. Nagy K, Varo G, Szalontai B (2012) $\kappa$-Casein terminates casein micelle build-up by its "soft" secondary structure. European Bio physics Journal 41: 959-968.

3. Aranaz I (2009) Functional Characterization of Chitin and Chitosan. Current Chemical Biology 3(2): 203-230.

4. Huang GQ Sun YT, Xiao JX, Yang J (2012) Complex coacervation of soybean protein isolate and chitosan. Food Chem 135: 534-539.

5. Turgeon SL, Schmitt C, Sanchez C (2007) Protein-polysaccharide complexes and coacervates. Curr Opin Coll Interf Sci 12: 166-178.

6. Kulikov S, Tikhonov V, Blagodatskikh I, Bezrodnykh E, Lopatin S, et al. (2012) Carbohydrate Polymers 87: 545-550. 